\title{
The Comparison of Water Cooling Media Against Radiator Heat Dissipation Rate in Diesel Engines
}

\section{Perbandingan Media Pendingin Air Terhadap Laju Pembuangan Panas Radiator pada Mesin Diesel}

\author{
Muhammad Sawaludin ${ }^{1}{ }^{*}$, Hasan Maksum ${ }^{1}$, Wagino ${ }^{1}$
}

\begin{abstract}
This research was motivated by the large number of consumer requests for mechanics in workshops to replace the radiator coolant in diesel engines with reguler water. This research used an experimental research approach. The experimental research was often used to find the effect of existing variable and to test the hypotheses. Based on the results of testing and data analysis that have been carried out can be seen: there was an average decrease in the temperature of the cooling media from the engine due to using the cooling media from the manufacturer, a decrease in the rate of heat dissipation between reguler water and Prestone on each rotation with an average of 4.97\%, the water with TOP 1 Coolant $5.11 \%$ and the water with Toyota SLCC at $6.64 \%$. Based on the analysis of research data and statistical tests, it was concluded that the use of cooling media from the manufacturer can increase the heat transfer coefficient of the working fluid of the radiator, so that it can reduce the engine heat level and increase the rate of coolant heat dissipation.
\end{abstract}

Keywords:

water cooling media, heat dissipation rate, radiators

\begin{abstract}
Abstrak
Penelitian ini dilatarbelakangi oleh banyaknya permintaan konsumen kepada mekanik di bengkel untuk mengganti air radiator pada mesin diesel dengan air biasa Penelitian ini digolongkan pada penelitian pendekatan eksperimen. Penelitian eksperimen sering digunakan untuk mencari pengaruh di antara variabel-variabel yang ada serta untuk pengujian hipotesis. Hasil pengujian dan analisis data yang telah dilakukan dapat diketahui: Terdapat rata-rata penurunan suhu media pendingin dari mesin akibat menggunakan media pendingin asal pabrikan, penurunan laju pembuangan panas antara air biasa dengan Prestone pada masing-masing putaran dengan rata-rata 4,97\%, air dengan TOP 1 Coolant 5,11\% dan air dengan Toyota SLCC sebesar 6,64\%. Berdasarkan analisis data penelitian dan uji statistik yang dilakukan disimpulkan bahwa penggunaan media pendingin asal pabrikan dapat memperbesar koefisien perpindahan panas fluida kerja radiator sehingga dapat menurunkan tingkat panas mesin dan meningkatkan laju pembuangan panas cairan pendingin
\end{abstract}

Kata kunci:

media pendingin air, laju pembuangan panas, radiator

${ }^{1}$ Jurusan Teknik Otomotif, Fakultas Teknik, Universitas Negeri Padang

JIn. Prof. Dr. Hamka Air Tawar Padang 25131 INDONESIA

*syawal.unp12@gmail.com

Submitted :September 13, 2020. Accepted : January 30, 2021. Published : January 31, 2021. 


\section{PENDAHULUAN}

Mesin diesel merupakan sistem penggerak utama yang banyak digunakan untuk sistem transportasi maupun penggerak stasioner. Dikenal sebagai jenis motor bakar yang mempunyai efisiensi tinggi, mesin diesel mengalami perkembangan dalam bidang otomotif. Mobil dapat bergerak karena mempunyai tenaga. Sumber tenaga berasal dari energi panas hasil pembakaran campuran udara dengan bahan bakar di dalam silinder yang diubah menjadi kerja mekanik. Pembakaran ini mengakibatkan kenaikan suhu mesin. Apabila keadaan ini tidak mendapatkan pendinginan yang baik maka suhu pembakaran akan mempengaruhi kerja mesin secara keseluruhan. Agar kerja mesin tidak terganggu, pada kendaraan mobil selalu dipasang radiator sebagai pendingin mesin.

Perangkat radiator terdiri dari saluran cairan pendingin masuk dan saluran keluar mesin, kipas pendingin yang dipasang didepan atau dibelakang radiator, tangki cadangan cairan pendingin radiator dan cairan pendingin. Cairan pendingin pada radiator mempunyai peran yang sangat penting dalam membuang panas mesin ke lingkungan. Sistem pendingin atau cooling system adalah sistem yang paling penting untuk menjaga mesin dapat bekerja secara maksimal. Bagian dari sistem pendingin yang paling penting tidak hanya saluran regulasi cairan (fluida) pendingin mulai dari radiator menuju mesin hingga bersirkulasi kembali ke radiator untuk didinginkan, tetapi juga tergantung pada jenis cairan (fluida) yang dipakai. Lazimnya fluida yang dipakai untuk sistem pendingin adalah coolant (radiator coolant). Tetapi yang terjadi masih banyak masyarakat yang menggunakan fluida pendingin dengan air biasa. Menggunakan air biasa sebagai pendingin radiator memang bisa dilakukan namun hanya untuk jangka waktu pendek, jika dalam jangka waktu yang lama menggunakan air biasa akan mengakibatkan radiator berkarat dan korosi.

Proses pendinginan juga akan kurang maksimal, karena air biasa kurang baik dalam proses menghantarkan panas. Hal ini akan menyebabkan mesin cepat panas dan akan memperpendek usia mesin. Penggunaan radiator coolant lebih baik karena coolant lebih bagus menghantarkan panas dari mesin sehingga mesin akan tetap terjaga suhunya. Masa penggunaan coolant lebih panjang, karena titik didih coolant.

Setelah peneliti melakukan survei data di beberapa bengkel otomotif, ternyata masih banyak permintaan konsumen kepada mekanik untuk mengganti air radiator nya dengan air biasa dan media pendingin yang tidak sesuai dengan rekomendasi pabrik, dengan alasan lebih murah dan praktis dibandingkan menggunakan media pendingin dari pabrik. Sebagian besar konsumen tidak memahami secara detail dampak dari penggunaan media pendingin mobil.

\section{METODA}

Penelitian ini menggunakan pendekatan eksperimen. Penelitian eksperimen menggunakan treatment atau perlakuan terhadap kelompok tertentu, dan setelah perlakuan yang dilakukan diadakan evaluasi untuk melihat pengaruhnya. Kelompok eksperimen pada penelitian ini adalah penambahan zat aditif cairan pendingin (radiator coolant), sedangkan kelompok kontrol pada penelitian ini adalah penggunaan air tanpa campuran, kemudian semua kelompok tersebut diberikan tes yang sama. Penelitian ini dimaksudkan untuk membandingkan tingkat panas mesin dan nilai pembuangan panas penggunaan beberapa jenis cairan pendingin radiator sebagai media pendingin mesin pada panter.

Penelitian ini didahului dengan melakukan pengamatan di beberapa bengkel otomotif. Kemudian peneliti melakukan pengujian eksperimen menggunakan mobil Isuzu Panter di Workshop Teknik Otomatif Universitas Negeri Padang. Dalam penelitian ini peneliti menggunakan intrumen pengumpulan data berupa thermometer digital, RPM Tester atau 
tachometer, cairan pendingin serta air tanpa campuran, stopwatch, flow meter, dan anemometer.

Metode pengumpulan data yang digunakan dalam penelitian ini adalah metode observasi atau eksperimen laboratorium, dimana pengumpulan data yang dilakukan dengan menggunakan seluruh alat indera yang ada atau percobaan secara langsung di laboratorium. Klarifikasi dilakukan dengan menganalisa hasil pengujian tingkat panas mesin mobil yang menggunakan media pendingin pabrikan dengan hasil pengujian tingkat panas mesin yang menggunakan beberapa jenis media pendingin.

Data yang telah dikumpulkan dari proses pengujian kemudian akan dianalisis untuk memperoleh tingkat perbedaan yang ditunjukkan indikator-indikator penelitian yang telah ditetapkan. Hasil akhir perhitungan tersebut berbentuk numeric (angka). Langkah selanjutnya adalah dengan menganalisis hasil pengujian tersebut dengan menggunakan tabel dan grafik.

\section{HASIL DAN PEMBAHASAN}

\section{Hasil}

Berikut data hasil penelitian laju pembuangan panas media pendingin penggunaan air biasa, Prestone, TOP 1, Toyota SLCC. Panas dari mesin akan didinginkan oleh radiator melalui sirkulasi sistem pendingin. Alat yang digunakan untuk mengukur suhu pembuangan panas dari mesin adalah thermometer, perbedaan laju pembuangan panas dari mesin diukur pada suhu kerja yang sama dengan penggunaan beberapa media pendingin sebagai fluida dapat dilihat pada tabel dibawah ini.

Tabel 1. Data hasil pengujian laju pembuangan panas dari mesin media pendingin radioator

\begin{tabular}{|c|c|c|c|c|c|}
\hline \multirow{2}{*}{$\begin{array}{c}\text { Variasi } \\
\text { Putaran }\end{array}$} & \multirow{2}{*}{$\begin{array}{c}\text { Waktu } \\
\text { Pengukuran }\end{array}$} & \multicolumn{4}{|c|}{ Media Pendingin Radiator } \\
\hline & & $\begin{array}{c}\text { Air } \\
\left(\mathrm{Th}_{\mathrm{i}}\left({ }^{\circ} \mathrm{C}\right)\right)\end{array}$ & $\begin{array}{l}\text { Prestone } \\
\left(\mathrm{Th}_{\mathrm{i}}\left({ }^{\circ} \mathrm{C}\right)\right)\end{array}$ & $\begin{array}{c}\text { TOP } 1\left(\mathrm{Th}_{\mathrm{i}}\right. \\
\left.\left({ }^{\circ} \mathrm{C}\right)\right)\end{array}$ & $\begin{array}{c}\text { SLCC }\left(\mathrm{Th}_{\mathrm{i}}\right. \\
\left.\left({ }^{\circ} \mathrm{C}\right)\right)\end{array}$ \\
\hline \multirow[t]{6}{*}{$800 \mathrm{Rpm}$} & 2 menit & 83,3 & 81,6 & 81,2 & 80,5 \\
\hline & 4 menit & 85,5 & 82,4 & 81,6 & 81,3 \\
\hline & 6 menit & 87,1 & 82,8 & 83,3 & 82,1 \\
\hline & 8 menit & 88,4 & 84,9 & 84,1 & 83,6 \\
\hline & 10 menit & 92,4 & 86,2 & 86 & 87,1 \\
\hline & Rata-rata & 87,34 & 83,58 & 83,24 & 82,92 \\
\hline \multirow[t]{6}{*}{$2400 \mathrm{Rpm}$} & 2 menit & 88,7 & 83,1 & 83,5 & 82,5 \\
\hline & 4 menit & 90,8 & 85,1 & 85,3 & 84,3 \\
\hline & 6 menit & 91,3 & 87,3 & 85,6 & 86,1 \\
\hline & 8 menit & 93,5 & 90,2 & 89,7 & 89,3 \\
\hline & 10 menit & 95,9 & 92,3 & 91,3 & 91,5 \\
\hline & Rata-rata & 92,04 & 87,6 & 87,08 & 86,74 \\
\hline \multirow[t]{6}{*}{$3200 \mathrm{Rpm}$} & 2 menit & 89,9 & 88,2 & 83,9 & 82,3 \\
\hline & 4 menit & 95,8 & 90,3 & 91,4 & 86,1 \\
\hline & 6 menit & 99,4 & 93,2 & 96,2 & 90,2 \\
\hline & 8 menit & 103,7 & 96,2 & 97,7 & 93,7 \\
\hline & 10 menit & 106,9 & 98,1 & 100,3 & 98,3 \\
\hline & Rata-rata & 99,14 & 93,2 & 94,44 & 90,12 \\
\hline
\end{tabular}


Pengukuran laju pembuangan panas dari mesin menggunakan media pendingin radiator yang sama pada variasi putaran dapat disimpulkan bahwa semakin tinggi putaran mesin semakin tinggi panas yang dihasilkan mesin, hal ini disebabkan oleh siklus pembakaran di dalam silinder yang semakin cepat dan semakin panas. Data-data yang digambarkan tersebut diketahui bahwa media pendingin radiator yang mengandung ethylene glycol mampu menurunkan laju pembuangan panas pada mesin karena fluid properties air biasa dan water coolant berbeda sehingga kemampuan menyerap panas hasil pembakaran berbeda.

Data-data pada tabel 1 tersebut diolah menggunakan rumus statistik untuk mengetahui seberapa besar pengaruh penggunaan beberapa jenis media pendingin radiator terhadap laju pembuangan panas mesin. Rumus $t$-test yang digunakan adalah:

$t=\frac{(\bar{x}-\bar{y})-\left(\mu_{x-} \mu_{y}\right)}{\sqrt{\frac{\left(n_{x}-1\right) s x^{2}+\left(n_{y}-1\right) s y^{2}}{n_{x}+n_{y}-2}} \sqrt{\frac{1}{n_{x}}+\frac{1}{n_{x}}}}$

Dimana :

Ho $=\left(\mu_{x-} \mu_{y}\right)=0$

$\bar{x} \quad=$ harga rata-rata sampel yang pertama

$\bar{y} \quad=$ harga rata-rata sampel yang kedua

$S X \quad=$ simpangan baku pada sampel yang pertama

sy $\quad$ = simpangan baku pada sampel yang kedua

$n_{x} \quad=$ jumlah sampel 1

$n_{y} \quad=$ jumlah sampel 2

Tabel 2. Hasil olah data laju pembuangan panas dari mesin menggunakan beberapa jenis median pendingin

\begin{tabular}{|c|c|c|c|c|c|c|c|c|c|}
\hline \multirow{2}{*}{$\begin{array}{c}\text { Putaran } \\
\text { (Rpm) }\end{array}$} & \multicolumn{9}{|c|}{ Hasil Uji t antara air (x) dengan Prestone (y) } \\
\hline & $\bar{x}$ & $\overline{\mathbf{y}}$ & $\mathbf{n}_{\mathbf{x}}$ & $\mathbf{n}_{\mathbf{y}}$ & $\mathbf{S}_{\mathbf{X}}$ & $\mathbf{S}_{\mathbf{y}}$ & T.tes & T.tabel & Signifikansi \\
\hline $800 \mathrm{Rpm}$ & 87,34 & 83,58 & 5 & 5 & 3,40925 & 1,90578 & 2,15263 & 2,132 & Signifikan \\
\hline 2400 & 92,04 & 87,6 & 5 & 5 & 2,751 & 3,7229 & 2,14477 & 2,132 & Signifikan \\
\hline 3200 & 99,14 & 93,2 & 5 & 5 & 6,66355 & 4,07492 & 1,70052 & 2,132 & $\begin{array}{l}\text { Tidak } \\
\text { Signifikan }\end{array}$ \\
\hline \multicolumn{10}{|c|}{ Hasil Uji t antara air (x) dengan TOP 1 Coolant (y) } \\
\hline $\begin{array}{l}\text { Puta } \\
\text { (Rpp }\end{array}$ & $\bar{x}$ & $\overline{\mathbf{y}}$ & $\mathbf{n}_{\mathbf{x}}$ & $\mathbf{n}_{\mathbf{y}}$ & $\mathbf{S}_{\mathbf{x}}$ & Sy & T.tes & T.tabel & Signifikansi \\
\hline 80 & 37,34 & 83,24 & 5 & 5 & 3,40925 & 1,95013 & 2,33424 & 2,132 & ifikan \\
\hline 240 & 92,04 & 87,08 & 5 & 5 & 2,751 & 3,27291 & 2,59407 & 2,132 & ifikan \\
\hline $3200 \mathrm{Rpm}$ & 99,14 & 94,44 & 5 & 5 & 6,66355 & 6,48841 & 1,12998 & 2,132 & $\begin{array}{l}\text { Tidak } \\
\text { Signifikan }\end{array}$ \\
\hline \multicolumn{10}{|c|}{ Hasil Uji t antara air (x) dengan Toyota SLCC (y) } \\
\hline $\begin{array}{l}\text { Putaran } \\
\text { (Rpm) }\end{array}$ & $\bar{x}$ & $\overline{\mathbf{y}}$ & $\mathbf{n}_{\mathbf{x}}$ & $\mathbf{n}_{\mathbf{y}}$ & $\mathbf{S}_{\mathbf{x}}$ & $\mathbf{S y}_{\mathbf{y}}$ & T.tes & T.tabel & Signifikansi \\
\hline $800 \mathrm{Rpm}$ & 87,34 & 82,92 & 5 & 5 & 3,40925 & 2,6023 & 2,30442 & 2,132 & Signifikan \\
\hline $2400 \mathrm{Rpm}$ & 92,04 & 86,74 & 5 & 5 & 2,751 & 2,65896 & 3,09758 & 2,132 & \\
\hline $3200 \mathrm{Rpm}$ & 99,14 & 90,12 & 5 & 5 & 6,66355 & 6,26594 & 2,20507 & 2,132 & Signifikan \\
\hline
\end{tabular}


Data-data yang telah dijabarkan pada tabel 2 diketahui bahwa penggunaan water coolant sebagai media pendingin mesin yang didinginkan oleh radiator pada umumnya dapat menyerap panas secara signifikan berdasarkan perhitungan uji $t$ yang telah dilakukan. Namun pada 3200 Rpm Prestone dan TOP 1 Coolant mampu menyerap panas dari mesin tetapi tidak signifikan.

Hasil pengujian kemudian dihitung dengan mengalisis datya secara deskriptif untuk mencari persentase laju pembuangan panas dari mesin dengan menggunakan rumus:

$P=\frac{N}{n} 100 \%$

Dimana:

$\mathrm{P}=$ Angka persentase yang didapatkan

$\mathrm{N}=$ Rata-rata pada jenis media pendingin sesuai spesifikasi

$\mathrm{n}$ = Rata-rata pada jenis media pendingin pembanding

Tabel 3. Analisis Persentase Laju Pembuangan Panas Antara Air dengan Prestone.

\begin{tabular}{|l|c|c|c|c|}
\hline Variasi & Waktu & \multicolumn{3}{|c|}{ Media Pendingin } \\
\cline { 3 - 5 } Putaran & Pengujian & Air (oC) & Prestone (oC) & P (\%) \\
\hline 800 Rpm & & 87,34 & 83,58 & 4,25 \\
\hline $2400 \mathrm{Rpm}$ & \multirow{2}{*}{ Rata-rata } & 92,04 & 87,6 & 4,85 \\
\cline { 3 - 5 } & & 99,14 & 93,2 & 5,87 \\
\hline $3200 \mathrm{Rpm}$ & &
\end{tabular}

Tabel 4. Analisis Persentase Laju Pembuangan Panas Antara Air dengan TOP 1 Coolant.

\begin{tabular}{|l|c|c|c|c|}
\hline \multirow{2}{*}{$\begin{array}{c}\text { Putaran } \\
\text { (Rpm) }\end{array}$} & \multirow{2}{*}{$\begin{array}{c}\text { Waktu } \\
\text { Pengujian }\end{array}$} & \multicolumn{3}{|c|}{ Media Pendingin } \\
\cline { 3 - 5 } & & Air (oC) & TOP 1 (oC) & P (\%) \\
\hline 800 Rpm & 87,34 & 83,24 & 4,65 \\
\cline { 3 - 5 } $2400 \mathrm{Rpm}$ & Rata-rata & 92,04 & 87,08 & 5,40 \\
\cline { 3 - 5 } & & 99,14 & 94,44 & 5,29 \\
\hline $3200 \mathrm{Rpm}$
\end{tabular}

Tabel 5. Analisis Persentase Laju Pembuangan Panas antara Air dengan Toyota SLCC.

\begin{tabular}{|l|c|c|c|c|}
\hline \multirow{2}{*}{$\begin{array}{c}\text { Putaran } \\
\text { (Rpm) }\end{array}$} & \multirow{2}{*}{$\begin{array}{c}\text { Waktu } \\
\text { Pengujian }\end{array}$} & \multicolumn{3}{|c|}{ Media Pendingin } \\
\cline { 3 - 5 } & & Air ( $\left.{ }^{\circ} \mathbf{C}\right)$ & SLCC ( $\mathbf{o}^{\circ} \mathbf{C}$ & P (\%) \\
\hline 800 Rpm & 87,34 & 82,92 & 5,04 \\
\cline { 3 - 5 } $2400 \mathrm{Rpm}$ & Rata-rata & 92,04 & 86,74 & 5,78 \\
\cline { 3 - 5 } & & 99,14 & 90,12 & 9,10 \\
\hline
\end{tabular}

Selain menghitung persentase laju pembuangan panas, peneliti juga menganalisis persentase nilai efektivitas radiator, dengan hasil sebagai berikut:

Tabel 6. Analisis Persentase nilai Efektivitas Radiator

\begin{tabular}{|c|c|c|r|}
\hline $\begin{array}{c}\text { Variasi } \\
\text { Putaran }\end{array}$ & $\begin{array}{c}\text { Air : Prestone } \\
\text { (\%) }\end{array}$ & $\begin{array}{c}\text { Air : TOP 1 } \\
\text { (\%) }\end{array}$ & Air : SLCC (\%) \\
\hline 800 Rpm & 9,78 & 32,93 & 18,75 \\
\hline $2400 \mathrm{Rpm}$ & 19,40 & 30,64 & 11,68 \\
\hline $3200 \mathrm{Rpm}$ & 43,23 & 57,78 & 52,04 \\
\hline
\end{tabular}

\section{Pembahasan}

Radiator merupakan komponen utama sistem pendingin kendaraan yang berfungsi sebagai pembuang panas hasil pembakaran yang harus selalu beroperasi dengan baik agar 
mesin beroperasi pada temperatur aman. Hasil pengujian laju perpindahan panas dari mesin menggunakan beberapa jenis media pendingin radiator dapat diketahui bahwa laju perpindahan panas dari mesin terhadap waktu mengalami perubahan. Semakin tinggi putaran mesin semakin besar pula tingkat panas yang dihasilkan mesin, hal tersebut terjadi karena siklus pembakaran lebih cepat dan campuran udara dan bahan bakar di dalam silinder meningkat sehingga menghasilkan panas yang tinggi. Panas tersebut harus dibuang oleh radiator melalui sirkulasi cairan pendingin oleh water pump melalui belt dan electrick fan agar kenaikan temperatur mesin tidak terlalu tinggi sampai terjadi overheat.

Hasil pengujian laju pembuangan panas pada beberapa jenis media pendingin radiator dapat diketahui bahwa semakin tinggi putaran mesin berbanding lurus dengan semakin tingginya persentase laju pembuangan panas semakin tinggi pula penyerapan panas mesin oleh fluida kerja radiator pada water jacket. Laju pembuangan panas cairan media pendingin sangat ditentukan selisih temperatur antara temperatur masuk dan keluar radiator dan cooling fan yang berputar karena mesin menghasilkan panas yang harus diserap cairan media pendingin. Semakin tinggi putaran mesin maka semakin besar laju aliran fluida kerja dan udara yang dipengaruhi belt yang dihubungkan dengan putaran mesin.

Laju efektivitas pembuangan panas radiator mengalami peningkatan akibat penggunaan media pendingin coolant. Efektivitas radiator mengalami peningkatan karena penggunaan media pendingin yang mengandung ethylene glycol, karena perbedaan koefisien perpindahan panas konveksi cairan pendingin. Penyerapan panas terjadi pada radiator dimana panas pembakaran yang tinggi dibawa fluida kerja radiator menuju radiator untuk didinginkan, udara yang dihisap kipas pendingin sehingga terjadi selisih panas antara suhu udara di belakang dan di depan radiator. Dapat disimpulkan bahwa proses pertukaran panas pada alat penukar panas kendaraan sangat dipengaruhi oleh kapasitas panas yang diserap fluida kerja radiator dan selisih suhu udara di depan dan di belakang radiator yang akan menghasilkan efektivitas radiator yang lebih baik.

\section{SIMPULAN DAN SARAN}

\section{Simpulan}

Terdapat perbedaan yang signifikan pada suhu air pendingin dari mesin yang hanya menggunakan air biasa jika dibandingkan dengan beberapa merek media pendingin asal pabrikan yakni Prestone, TOP 1 Coolant dan Toyota SLCC. Terdapat rata-rata penurunan suhu media pendingin dari mesin akibat menggunakan media pendingin asal pabrikan, penurunan laju pembuangan panas antara air biasa dengan Prestone pada masing-masing putaran dengan rata-rata 4,97\%, air dengan TOP 1 Coolant 5,11\% dan air dengan Toyota SLCC sebesar $6,64 \%$. Analisis statistik data penelitian menggunakan uji $t$, didapatkan nilai thitung pada taraf signifikan 5\% penggunaan beberapa media pendingin.

Hasil uji antara air dengan Prestone pada kecepatan 800 Rpm adalah sebesar 2,152 dengan $d f$ sebesar 4 maka $t_{\text {tabel }}$ yaitu sebesar 2,132, jika dibandingkan maka nilai thitung lebih besar dari nilai ttabel yaitu 2,152 > 2,132, hal ini menunjukkan hipotesis yang diajukan diterima pada taraf signifikansi 5\%. Pada $2400 \mathrm{Rpm}$ pengujian didaptkan hasil nilai thitung sebesar 2,145 dengan $d f$ sebesar 4 maka tabel yaitu sebesar 2,132, jika dibandingkan maka nilai thitung lebih besar dari nilai $t_{\text {tabel }}$ yaitu 2,152 $>2,132$, hal ini menunjukkan hipotesis yang diajukan diterima pada taraf signifikansi 5\%. Sedangkan pada 3200 Rpm pengujian didaptkan hasil nilai thitung sebesar 1,701 dengan $d f$ sebesar 4 maka tabel yaitu sebesar 2,132, jika dibandingkan maka nilai thitung lebih kecil dari nilai tabel yaitu 1,701<2,132, hal ini menunjukkan hipotesis yang diajukan ditolak pada taraf signifikansi $5 \%$. 
Hasil uji antara air dengan TOP 1 Coolant pada kecepatan 800 Rpm adalah sebesar 2,334 dengan $d f$ sebesar 4 maka $t_{\text {tabel }}$ yaitu sebesar 2,132, jika dibandingkan maka nilai $t_{\text {hitung }}$ lebih besar dari nilai $t_{\text {tabel }}$ yaitu 2,334 > 2,132, hal ini menunjukkan hipotesis yang diajukan diterima pada taraf signifikansi 5\%. Pada $2400 \mathrm{Rpm}$ pengujian didaptkan hasil nilai thitung sebesar 2,594 dengan $d f$ sebesar 4 maka tabel yaitu sebesar 2,132, jika dibandingkan maka nilai thitung lebih besar dari nilai ttabel yaitu 2,594 $>2,132$, hal ini menunjukkan hipotesis yang diajukan diterima pada taraf signifikansi 5\%. Sedangkan pada $3200 \mathrm{Rpm}$ pengujian didaptkan hasil nilai thitung sebesar 1,13 dengan $d f$ sebesar 4 maka $t_{\text {tabel }}$ yaitu sebesar 2,132, jika dibandingkan maka nilai thitung lebih kecil dari nilai ttabel yaitu 1,13 $<2,132$, hal ini menunjukkan hipotesis yang diajukan ditolak pada taraf signifikansi 5\%.

Hasil uji antara air dengan Toyota SLCC pada kecepatan $800 \mathrm{Rpm}$ adalah sebesar 2,304 dengan $d f$ sebesar 4 maka ttabel yaitu sebesar 2,132, jika dibandingkan maka nilai thitung lebih besar dari nilai ttabel yaitu 2,304 > 2,132, hal ini menunjukkan hipotesis yang diajukan diterima pada taraf signifikansi 5\%. Pada $2400 \mathrm{Rpm}$ pengujian didaptkan hasil nilai thitung sebesar 3,097 dengan $d f$ sebesar 4 maka tabel yaitu sebesar 2,132, jika dibandingkan maka nilai $t_{\text {hitung }}$ lebih besar dari nilai $t_{\text {tabel }}$ yaitu 3,097 $>2,132$, hal ini menunjukkan hipotesis yang diajukan diterima pada taraf signifikansi 5\%. Sedangkan pada 3200 Rpm pengujian didaptkan hasil nilai thitung sebesar 2,205 dengan $d f$ sebesar 4 maka tabel yaitu sebesar 2,132, jika dibandingkan maka nilai thitung lebih besar dari nilai ttabel yaitu 2,205 > 2,132, hal ini menunjukkan hipotesis yang diajukan diterima pada taraf signifikansi 5\%.

\section{Saran}

Bagi masyarakat khususnya pemilik kendaraan diesel sebaiknya selalu memperhatikan kualitas fluida media pendingin kerja yang digunakan pada radiator kendaraan. Penggunaan media pendingin yang di rekomendasikan oleh pabrikan mobil mengandung ethylene glycol yang lebih baik digunakan sebagai media pendingin radiator, jika dibandingkan dengan penggunaan air biasa karena dapat menurunkan tingkat panas mesin dan meningkatkan laju pembuangan panas radiator kendaraan sehingga penggunaan media pendingin pabrikan dapat mengatasi permasalahan terkait peningkatan temperatur yang tidak normal pada kendaraan. Penelitian ini dapat dikembangkan dengan memberikan pembebanan pada mesin, seperti dengan menghidupkan Air Conditioner (AC) dan kelengkapan kelistrikan (misalnya lampu) serta dilakukan analisis terhadap laju pembuangan panas cairan pendingin dan konsumsi bahan bakar.

\section{DAFTAR RUJUKAN}

[1] Aprianto, Erwan. “Analisa Unjuk Kerja Perpindahan Panas Air Cooler Generator Tipe Plate Finned-Tubes Compact Heat Exchanger Pada Unit 7 PLTA Cirata," Universitas Jenderal Achmad Yani, Cimahi, 2017.

[2] Ariga, Dwi Randa, "Perbandingan Penggunaan Aditif Pada Sistem Pendingin Air Terhadap Tingkat Panas Mesin Mobil Toyota Avanza 1,3 G M/T,” Universitas Negeri Padang, Padang, 2015.

[3] Bintoro, "Pemeliharaan Mesin Kendaraan Ringan. Malang," Jakarta: Kementerian Pendidikan \& Kebudayaan Republik Indonesia, 2013.

[4] Caterpillar. "Student Handout: Engine Induction Course," Training Centre Trakindo Kuala Kencana, Papua, 2002.

[5] Daryanto, Reparasi Sistem Pendingin pada Mobil, Jakarta: PT. Rineka Cipta, 1994.

[6]Gupta, HN, Fundamentals of Internal Combution Engine, New Delhi: PHI Learning private limited, 2009. 
[7] Haryadi dan Ali Mahmudi. Buku Bahan Ajar: Perpindahan Panas, Bandung. 2012

[8] Hidayat, Nuzul. Ahmad Arif. Martias, "Perbandingan Kemampuan Pelepasan Panas pada Alat Penukar Panas Radiator Straight Fin Jenis Circular Cylinder Tube dengan Flat Tube," Jurnal Inovasi Vokasional dan Teknologi, vol. 19 No. 1 pp. 18-20, 2019.

[9]Holman, J.P. Heat Transfer. New York: McGraw-Hill Book Co, ISBN 978-0-07-352936-3, 2010.

[10] Maksum, Hasan. dkk, "Pengaruh Variasi Cairan Pendingin (Coolant) Terhadap Efektivitas Radiator Pada Engine Diesel," Automotive Engineering Education Journals, vol. 2 No. 2, 2017.

[11] Maryono, Budi, Memperbaiki Radiator Assy, Yogyakarta: PT Citra Aji Parama, 2012.

[12] Mustamant, Pengetahuan Mesin dan Onderdil Mobil, Bandung: Mitra Edukasi Indonesia, 2014. 